'Instituto Agronômico de Pernambuco (IPA), Av. General San Martin, 1371 , CEP 50761-000, Recife, PE, Brasil

${ }^{2}$ Departamento de Bioquímica, Universidade Federal de Pernambuco (UFPE), Recife, PE, Brasil

${ }^{3}$ Departamento de Micologia Universidade Federal de Pernambuco (UFPE), Recife, PE, Brasil

*autor correspondente

$\nabla$ rs.lopes@hotmail.com

\title{
Aspectos biológicos de espécies de Isaria (Persoon) após infecção sobre Sitophilus zeamais Motschulsky (Coleoptera: Curculionidae)
}

\section{Biological aspects Isaria species (Persoon) after infection on Sitophilus zeamais Motschulsky (Coleoptera: Curculionidae)}

Rosineide da Silva Lopes ${ }^{1 *}$, Geiziquele de Lima ${ }^{1}$, Luciana Gonçalves de Oliveira ${ }^{1}$,

Antonio Félix da Costa ${ }^{1}$, Maria Tereza dos Santos Correia², Elza Áurea de Luna Alves Lima ${ }^{3}$,

Vera Lúcia Menezes Lima²

RESUMO: O objetivo do trabalho foi analisar os aspectos biológicos de Isaria farinosa, I. javanica e I. fumosorosea antes e após infecção de Sitophilus zeamais. Insetos adultos, infectados com as linhagens das três espécies em laboratório, foram semeados em meio Sabouraud (SAB) com cloranfenicol e, após 12 dias, os reisolados foram comparados com as linhagens não inoculadas nos insetos, por meio de avaliação das microestruturas, germinação dos conídios, crescimento micelial e produção de conídios. Esses experimentos foram conduzidos à temperatura de $28 \pm 1^{\circ} \mathrm{C}$. Os reisolados dos fungos produziram conidióforos, conídios e apressórios em maior quantidade em relação às linhagens-padrão. Constatou-se diferença estatística na germinação das linhagens antes e após o reisolamento, exceto de I. javanica URM4993 e I. fumosorosea ESALQ1296. Todos os reisolados diferiram das demais linhagens, sendo que o crescimento micelial foi maior do que os das linhagens-padrão. Houve diferença estatística entre a média da esporulação das linhagens-padrão e dos respectivos reisolados, exceto I. farinosa ESALQ1355, mas o reisolado produziu maior quantidade de conídios. Estes resultados indicam o revigoramento e a viabilidade desses fungos após o reisolamento a partir de $S$. zeamais, sugerindo sua produção para testes no controle do inseto in vitro e em campo.

palavras-chave: controle biológico, revigoramento, fungos entomopatogênicos.
ABSTRACT: The aim of the study was to analyze biological aspects of Isaria farinosa, I. javanica and I. fumosorosea before and after Sitophilus zeamais infection. Adult insects infected in laboratory with these strains were grown in Sabouraud (SAB) with chloramphenicol, and after 12 days, the reisolated fungi was compared with strains not reisolated, through the evaluation of microstructures, germination, mycelial growth and conidial production, and the experiments were conducted at temperature of $28 \pm 1{ }^{\circ} \mathrm{C}$. The reisolated fungi produced conidiophores, conidia and apressoria in higher quantity in relation to standard-strains. Statistical difference was found in the germination of the strains after reisolation, except for I. javanica URM4993 and I. fumosorosea ESALQ1296. All isolates were different and the mycelial growth was greater than those of standard-strains. There was statistical difference sporulation mean of standard-strains and their reisolated, except the I. farinosa ESALQ1355, but produced more amount of conidia reisolated. These results indicate the reinvigoration and viability of the reisolation of S. zeamais suggesting its production in insect control tests in vitro and field.

keywords: biological control, reinvigoration entomopathogenic fungi. 


\section{Introdução}

Sitophilus zeamais Motschulsky (Coleoptera: Curculionidae) é uma das principais pragas do milho armazenado, cuja infestação torna o produto impróprio para a industrialização, para a alimentação humana e de animais (NGAMO et al., 2007; RONDELLI et al., 2012). O gorgulho do milho rompe o grão e se alimenta do endosperma, possibilitando a instalação de outros agentes de deterioração, o que causa prejuízos na qualidade e comercialização do milho (GALLO et al., 2002). O controle dessa praga é feito pela utilização de inseticidas, especialmente por meio de expurgo com fosfina (fosfeto de alumínio ou fosfeto de magnésio), tóxicos ao ambiente, ao homem e possibilita a seleção de populações de insetos resistentes (GALLO et al., 2002; NGAMO et al., 2007).

Os fungos entomopatogênicos são uma alternativa para o controle de insetos-praga, visto que são versáteis e possuem mecanismos de infecção especializados, infectam os estágios do ciclo de vida do hospedeiro, penetrando por diversas vias, em especial, o tegumento, sendo que os demais organismos infectam os insetos através da ingestão (ALVES, 1998; FANG et al., 2009). Assim, espécies de entomopatógenos como Beauveria bassiana (Balsamo) Vuillemin e Metarhizium anisopliae (Mestsch) Sorokin são testadas com sucesso e agem no controle de $S$. zeamais (POTRICH et al., 2006, 2010). Mas, esses entomopatógenos podem perder a capacidade de infecção devido ao tempo de estocagem em Coleções de Culturas em Micotecas, às sucessivas repicagens para a aplicação sobre as pragas e à exposição a altas temperaturas. Por isso faz-se necessário o revigoramento desses fungos após a infecção em insetos-alvo, antes de serem usados em bioensaios de patogenicidade. Segundo Passos et al. (2014), linhagens de Isaria analisadas apresentaram germinação superior a $95 \%$ após o reisolamento de Coptotermes gestroi (Wasmann) demonstrando o revigoramento e a alta capacidade germinativa das mesmas.

No gênero Isaria Persoon (= Paecilomyces) estão reunidas espécies entomopatogênicas que são eficazes no controle biológico (ALVES, 1998). I. farinosa (Holm: Fries) Fries é citada na literatura como patogênica a várias espécies de insetos, como Pissodes punctatus Langor \& Zhang, Planococus citri (Risso) e C. gestroi, entre outros (YANG et al., 2009; DEMIRCI et al., 2011; PASSOS et al., 2014). Isaria fumosorosea (Wize) Brown \& Smith é isolada de uma variedade de insetos, sendo sua eficiência comprovada no controle de Plutella xylostella L., Coptorermes formosanus (Shiraki), Diaphorina citri Kuwayama, Panonychus ulmi (Koch), entre outros (XU et al., 2011; MEYLING; SCHMIDT; EILENBERG, 2012; WRIGHT; LAX, 2013; GRÄFF et al., 2017). Isaria javanica (Frieder \& Bally) Samson \& Hywell-Jones é um entomopatógeno eficiente no controle de insetos-praga como: Trialeurodes vaporariorum (Westwood), Lonomia obliqua Walker e Hyalopterus pruni Geoff e Aphis pomi (DeGeer), (SCORSETTI et al., 2008; SPECHT et al., 2009; HASAN; ASSAF; ABDULLAH, 2012).

Considerando a importância do controle de S. zeamais para o armazenamento e na manutenção da qualidade do milho armazenado, este estudo objetivou avaliar os aspectos biológicos de I. farinosa, I. fumosorosea e I. javanica antes e após a infecção de S. zeamais, visando o revigoramento dessas espécies fúngicas e sua utilização no controle do inseto.

\section{Material e Métodos}

As linhagens I. farinosa (URM5016, URM5060, ESALQ1205 e ESALQ1355), I. javanica (URM4993 e URM4995) e I. fumosorosea (ESALQ1296 e ESALQ1297), cedidas pela Micoteca/URM, do Departamento de Micologia, da Universidade Federal de Pernambuco/UFPE e pela Micoteca do Departamento de Fitossanidade, da Universidade Federal Rural de Pernambuco/UFRPE, foram cultivadas em tubos de ensaio, contendo o meio Sabouraud (SAB), por 12 dias. Em seguida, conídios foram transferidos para tubo de ensaio contendo $10 \mathrm{~mL}$ da solução de Tween $80(0,1 \%$ v/v) e quantificados em câmara de Neübauer, para a obtenção de uma suspensão de $1 \times 10^{8}$ conídios/ $\mathrm{mL}$, conforme metodologia de Alves e Morais (1998).

Os insetos adultos foram obtidos da Criação de Insetos do Laboratório de Citologia e Genética de Fungos, do Departamento de Micologia/UFPE. Dez espécimes de S. zeamais foram transferidos para potes plásticos, e em seguida foram pulverizados (pulverizador manual) com $0,5 \mathrm{~mL}$ de uma suspensão $1 \times 10^{8}$ conídios $/ \mathrm{mL}$ de cada uma das linhagens fúngicas, separadamente. $O$ experimento foi realizado em triplicada, com monitoramento diário, durante 12 dias. Os insetos mortos foram desinfetados (álcool 70\%, hipoclorito de sódio a 4\% e água destilada autoclavada) de acordo com Alves et al. (1998). Após a assepsia, os insetos foram transferidos para câmara úmida e mantidos em estufa BOD (Biological Oxigen Demand) à temperatura de $28 \pm 1^{\circ} \mathrm{C}$, até o crescimento e esporulação fúngica. Em seguida, as estruturas dos entomopatógenos foram semeadas em placas de Petri, contendo SAB, acrescido de antibiótico (Cloranfenicol a $2 \%$ ), para o reisolamento das linhagens. Após cinco dias, as linhagens foram transferidas para tubos de ensaio com SAB, aguardando a esporulação por 12 dias, para serem utilizadas nos bioensaios. Convencionou-se como linhagem-padrão (P) as linhagens de I. farinosa, I. javanica e I. fumosorosea provenientes das Micotecas e, reisolado (R), as linhagens após reisolamento a partir de $S$. zeamais. Posteriormente, foram analisados os aspectos biológicos de ambos os tipos de linhagens com o objetivo de conhecer as características morfológicas dos fungos, bem como o revigoramento dos mesmos.

Os aspectos biológicos foram avaliados por meio da análise das microestruturas, germinação, crescimento micelial e produção de conídios. A análise das microestruturas foi realizada de acordo com a técnica descrita por Domsch et al. (2007), sendo o inóculo das linhagens ( $\mathrm{Pe} \mathrm{R}$ ) transferido assepticamente para quatro pontos equidistantes de uma placa de Petri com SAB e coberto por lamínula previamente flambada. As placas foram mantidas à temperatura de $28 \pm 1^{\circ} \mathrm{C}$ e às $24,48,72$ e 96 horas, uma lamínula foi retirada, colocada invertida sobre uma lâmina, corada com azul de Amann e analisada ao microscópio óptico. Para análise da germinação dos conídios, $0,1 \mathrm{~mL}$ da suspensão $1 \times 10^{8}$ conídios $/ \mathrm{mL}$ de cada linhagem (P e R) foi inoculado em placas de Petri com SAB e espalhado com o auxílio de alça de Drigalsky, sendo mantidas à temperatura de $28 \pm 1^{\circ} \mathrm{C}$. O percentual de germinação foi determinado 
contando-se 500 conídios (entre os conídios germinados e os não germinados) por placa, 16 horas após a semeadura, utilizando a seguinte fórmula: $\mathrm{G}=\mathrm{n} \times 100 / 500$, onde $\mathrm{G}$ e $\mathrm{n}$ equivalem ao percentual de germinação e ao número de conídios germinados, respectivamente, conforme o protocolo de Alves e Pereira (1998). Para se estimar o crescimento micelial, disco de $0,3 \mathrm{~mm}$ de papel filtro inoculado com $0,01 \mathrm{~mL}$ da suspensão $\left(1 \times 10^{8}\right.$ conídios $\left./ \mathrm{mL}\right)$ de cada linhagem (P e R) foi transferido para o centro de uma placa de Petri com SAB. As placas foram mantidas à temperatura $28 \pm 1^{\circ} \mathrm{C}$ e, após 12 dias foram mensurados os diâmetros das colônias. Na avaliação da esporulação fúngica, a colônia foi cortada e transferida para um tubo de ensaio contendo $10 \mathrm{~mL}$ de solução Tween $80(0,1 \%$ v/v). A suspensão foi agitada por aproximadamente dois minutos em Vórtex e, em seguida, foi quantificada em câmara de Neübauer.

O delineamento utilizado para os bioensaios em laboratório foi inteiramente casualizado, com cinco repetições, exceto o microcultivo, sendo os dados submetidos à análise de variância com o teste $\mathrm{F}$ e as médias comparadas pelo teste de Tukey, a $5 \%$ de probabilidade.

\section{Resultados e Discussão}

As estruturas vegetativas e reprodutivas dos fungos foram analisadas pela técnica de cultura em lamínula. Nas primeiras 24 horas apenas foram visualizadas estruturas miceliais, tanto nas linhagens-padrão quanto nos reisolados. Após 48 horas, em I. farinosa (ESALQ1205 e ESALQ1355) foi constatada a produção de conidíoforos, conídios e apressórios em maior quantidade nos reisolados (Figura 1. a, b, c, d, e). Entretanto, I. farinosa URM5016 e I. farinosa URM5060 formaram conidióforos e conídios (Figura 1.f, g) em torno de 72 horas, em maior proporção nos reisolados, sendo evidenciados apressórios apenas em I. farinosa URM5060, no período analisado (Figura 1. h). Todas as linhagens de $I$. farinosa apresentaram conidióforos jovens e em ramos verticilados, com duas a quatro fiálides de porção basal intumecida, terminando em um distinto pescoço alongado, as quais produzem e sustentam os conídios catenulados e elipsóides. Os apressórios apresentararam-se de forma simples e bifurcada, estrutura importante no processo de infecção e penetração no inseto hospedeiro. Estas características estão de acordo com as descritas por Samson (1974) e por Alves (1998). Também Szentiványi et al. (2006) identificaram pelas microestruturas, I. farinosa associado com oídio, Blumeria graminis Mehltau, em folhas de cevada.

Para I. javanica URM4993, às 48 horas a partir do plantio em meio de cultura foi constatada a formação de apressórios, conidíoforos e conídios (Figura 1. i, j, 1), sendo estas estruturas, principalmente os apressórios, produzidas em maior quantidade no reisolado, a partir de 72 horas. Contudo, I. javanica URM4995 formou apressórios, conidióforos e conídios (Figura 1. m, n, o) a partir de 72 horas, sendo as estruturas observadas em maior proporção no reisolado, a partir de 96 horas. As linhagens formaram conidióforos jovens ou em ramos verticilados, com duas a três fiálides, de porção basal cilíndrica, que termina em um distinto pescoço delgado, sendo essas produtoras de conídios cilíndricos e catenulados. Os apressórios simples e bifurcados, sendo estes últimos em menor quantidade. Estas características são peculiares da espécie (SAMSON, 1974). Specht et al. (2009) classificaram como I. javanica, um fungo isolado da lagarta L. obliqua, usando como base a morfologia das estruturas (hifas, conidióforos, fiálides e conídios) e o sequenciamento do DNA, mostrando, assim, a importância das características morfológicas para a identificação de fungos entomopatogênicos utilizados no controle biológico de insetos-praga.

Isaria fumosorosea ESALQ1297 formou condióforos e conídios a partir de 72 horas, sendo observado em maior quantidade no reisolado, porém os apressórios foram produzidos em abundância nos reisolados já a partir de 48 horas (Figura 1. q, s). Já em I. fumosorosea ESALQ1296, conidióforos, conídios e apressórios (Figura 1.p, r) foram evidenciados após 96 horas, sendo produzidos em maior quantidade nas linhagens reisoladas. As linhagens apresentaram conidióforos jovens ou em ramos verticilados, dispostos lateralmente na hifa, formando uma estrutura complexa. Os conidióforos são formados por duas a cinco fiálides com uma porção basal globosa ou elipsóide que terminam em um longo pescoço distinto, as quais produzem conídios cilíndricos alongados, dispostos de forma catenulada. Ainda produziram apressórios simples e bifurcados, porém o último em menor proporção. Estas características são peculiares da espécie, conforme reportado por Samson (1974), o qual evidenciou a disposição complexa dos conidióforos, a quantidade, a forma das fiálides e os conídios que variam de cilíndrico a fusiforme.

De acordo com os estudos aqui conduzidos,não foram evidenciadas diferenças morfológicas entre as estruturas vegetativas e reprodutivas das linhagens-padrão e dos reisolados, embora as estruturas formadas tenham se apresentado em maior quantidade nos reisolados. Esses resultados estão de acordo com os encontrados por Lopes et al. (2008) que, ao estudar os aspectos biológicos de I. farinosa após a infecção sobre os operários do cupim subterrâneo $C$. gestroi, verificaram o revigoramento de duas linhagens devido à maior formação de estrututas vegetativas e reprodutivas nos reisolados. Os dados obtidos constataram o revigoramento das linhagens, após a passagem pelos adultos de $S$. zeamais, técnica utilizada para ativar a patogenicidade das linhagens fúngicas estocadas em substratos artificiais por um longo período de tempo (ALVES, 1998).

O percentual de germinação às 16 horas da inoculação diferiu estatisticamente entre a linhagem-padrão e o reisolado de cada fungo, exceto em I. javanica URM4993 e I. fumosorosea ESALQ1296. Entretanto, após a passagem pelo inseto não foi observada diferença significativa entre as linhagens, confirmando assim o revigoramento dos fungos pelos bons percentuais de germinação, os quais variaram de 75,20\% a 97,60\% (Tabela 1). Esses dados foram semelhantes ao percentual de conídios germinados após 24 horas da inoculação, obtidos por Barson et al. (1994), ao observarem a viabilidade de $I$. farinosa MI114831 isolado de Smerinthus ocellata (L.). De acordo com Lopes et al. (2011), a germinação de I. javanica URM4993 e URM4995 aumentou após o reisolamento das linhagens a partir de C. gestroi, sendo que os percentuais de germinação variaram de 94,04 e 89,92\% para a linhagem-padrão, enquanto 


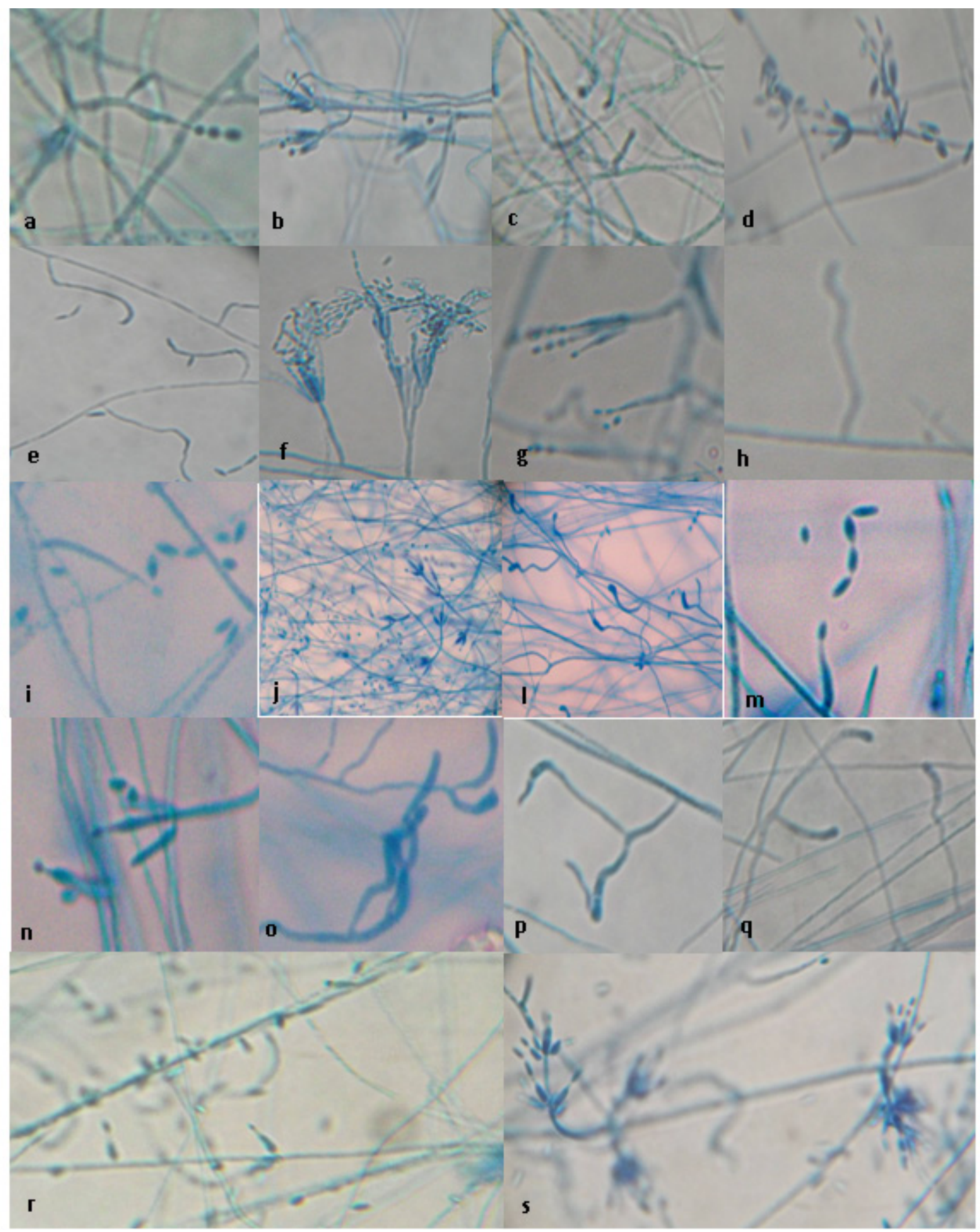

Figura 1. Microestruturas das linhagens de Isaria reisoladas a partir de Sitophilus zeamais (40X): conidióforo simples e conídios catenulados (a), conidióforos verticilados (b) e apressórios simples (c) de Isaria farinosa ESALQ1205, conidióforos verticilados, conídios (d) e apressórios simples (e) de Isaria farinosa ESALQ1355, conidióforos verticilados e conídios catenulados (f) de Isaria farinosa URM5016, conidióforos verticilados, conídios (g) e apressórios simples (h) de Isaria farinosa URM5060; conidióforo simples e conídios catenulados (i), conidióforos verticilados (j) e apressórios simples e bifurcadas (1) de Isaria javanica URM4993, conidióforo simples, conídios catenulados (m), conidióforos (n) e apressórios bifurcados (o) de Isaria javanica URM4995; apressório bifurcado (p) e conidióforos em ramos verticilados (r) de Isaria fumosorosea ESALQ1296, apressório simples e bifurcado (q) e conidióforos em ramos verticilados (s) de Isaria fumosorosea ESALQ1297.

para os reisolados de I. javanica URM4993 e URM4995 foram de 98,24 e 97,76\%, respectivamente. Segundo Alves (1998), a germinação é um fator descisivo no controle microbiano, pois uma taxa elevada de esporos germinados é diretamente proporcional à virulência de linhagens fúngicas.

Como demonstrado na Tabela 1 , foram encontradas diferenças estatísticas entre as linhagens-padrão e reisolados, sendo que estas apresentaram maior média no crescimento micelial, variando de 2,54 a 4,52 cm. Esses dados estão de acordo com os obtidos por Lopes et al. (2008), quando avaliaram o crescimento micelial de I. farinosa antes e após a passagem por C. gestroi, tendo sido verificado que o diâmetro da colônia aumentou na cultura reisolada. Por outro lado, Samson (1974) observou ótimo crescimento da colônia de I. farinosa, I. fumosorosea e I. javanica 


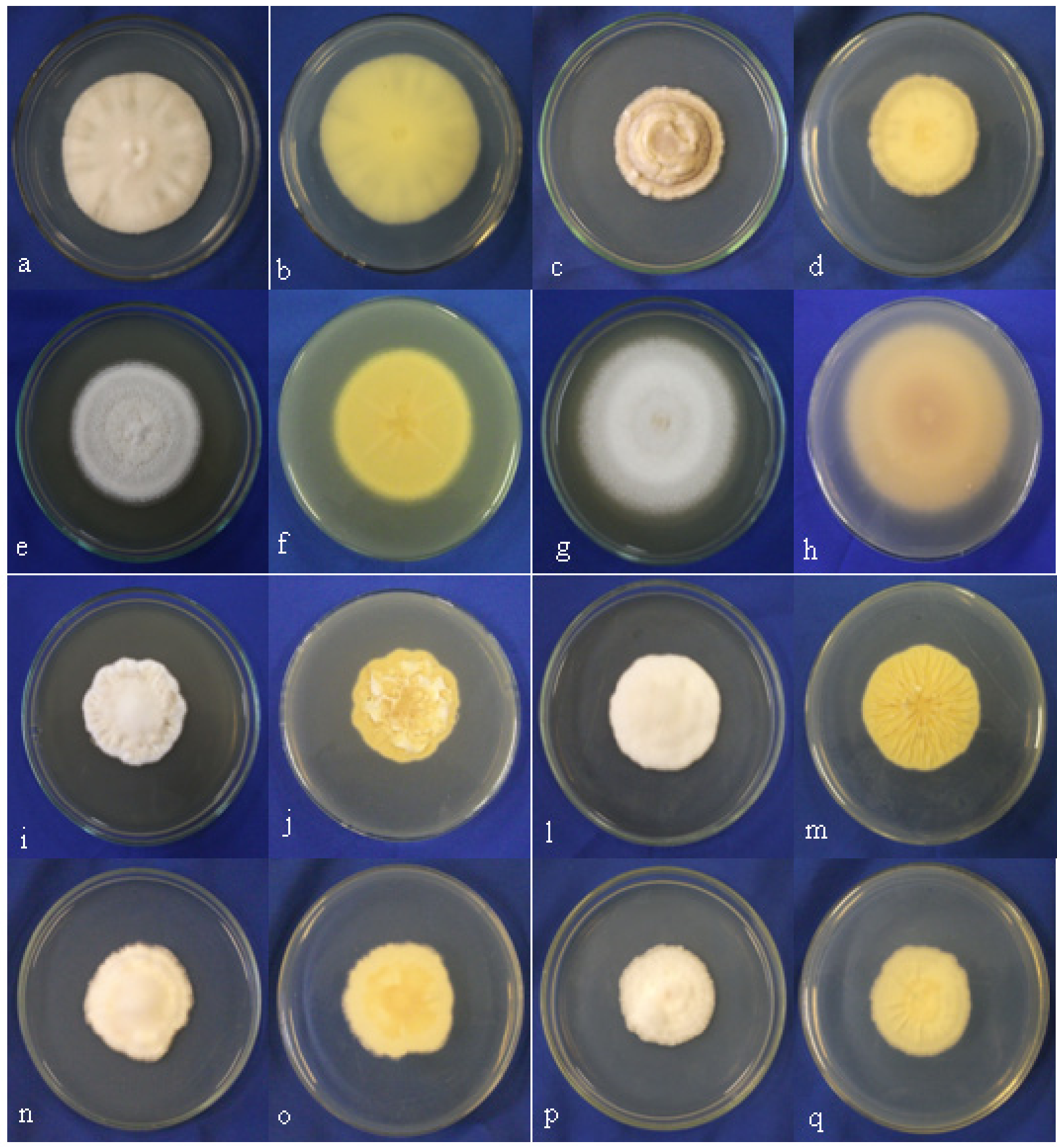

Figura 2. Aspecto do verso e reverso das colônias das linhagens reisoladas a partir de Sitophilus zeamais, em meio SAB, após 12 dias: Isaria farinosa ESALQ1205 (a, b), Isaria farinosa ESALQ1355 (c, d), Isaria farinosa URM5016 (e, f), Isaria farinosa URM5060 (g, h), Isaria javanica URM4993 (i, j), Isaria javanica URM4995 (1, m), Isaria fumosorosea ESALQ1296 (n, o) e Isaria fumosorosea ESALQ1297 (p, q).

em Ágar-Malte, atingindo diâmetro de dois a quatro centímetros após 14 dias. De acordo com a tabela de cores proposta por Villalobos-Dominguez e Villalobos (1947) para microrganismos, I. farinosa ESALQ1205 apresentou colônia de aspecto flocoso, de coloração rósea $\left(\mathrm{R} 19-3^{\circ}\right)$ e reverso amarelo (yyL19-3 $3^{\circ}$ (Figura 2. a, b) enquanto I. farinosa ESALQ1355 formou colônia de aspecto pulverulento, de coloração cinza $\left(\mathrm{R} 16-2^{\circ}\right)$ e reverso creme $\left(0 \gamma 19-3^{\circ}\right)$ (Figura 2. c, d). Também I. farinosa URM5016 apresentou colônia de aspecto pulverulento, de coloração creme (yy019) e reverso creme (yy019-9 ${ }^{\circ}$ ) (Figura 2. e, f). Enquanto I. farinosa URM5060 formou colônia de aspecto flocoso, de cor branca e reverso creme (yy019-9 ${ }^{\circ}$ (Figura 2. g, h). Conforme Samson (1974), I. farinosa pode formar colônia de aspecto flocoso, às vezes pulverulento, de coloração que varia de branca a creme e o reverso de cor amarela a creme. I. javanica URM4993 formou colônia de aspecto flocoso, de cor branca e reverso amarelo $\left(\gamma 19-3^{\circ}\right)$ (Figura 2. i, j). Enquanto I. javanica URM4995 apresentou colônia de aspecto cotonoso, de cor branca e reverso amarelo $\left(\gamma 19-6^{\circ}\right)$ (Figura 2. 1, m), sendo estas características descritas como peculiares da espécie. I. fumosorosea ESALQ1296 formou colônia de aspecto flocoso, de cor branca e reverso amarelo $\left(\gamma 19-3^{\circ}\right)$ (Figura 2. n, o). 
Tabela 1. Aspectos biológicos (germinação, crescimento micelial e produção de conídios) de espécies de Isaria, antes e após infecção de Sitophilus zeamais

\begin{tabular}{|c|c|c|c|c|c|c|}
\hline \multirow{3}{*}{ Linhagens } & \multicolumn{6}{|c|}{ Aspectos biológicos } \\
\hline & \multicolumn{2}{|c|}{ Germinação (\%) } & \multicolumn{2}{|c|}{ Crescimento Micelial (cm) } & \multicolumn{2}{|c|}{$\begin{array}{c}\text { Esporulação } \\
\left(1 \times 10^{7} \text { conídios } / \mathrm{mL}\right)\end{array}$} \\
\hline & $\mathbf{P}^{1}$ & $\mathbf{R}^{2}$ & $\mathbf{P}$ & $\mathbf{R}$ & $\mathbf{P}$ & $\mathbf{R}$ \\
\hline Isaria fumosorosea ESALQ1296 & $85,28 \mathrm{abB}$ & $96,16 \mathrm{aA}$ & $2,54 \mathrm{~dB}$ & $2,67 \mathrm{gA}$ & $1,04 \mathrm{cA}$ & $2,00 \mathrm{dA}$ \\
\hline Isaria fumosorosea ESALQ1297 & $67,04 \mathrm{deB}$ & $90,08 \mathrm{aA}$ & $2,25 \mathrm{eB}$ & $2,54 \mathrm{fgA}$ & $1,20 \mathrm{cA}$ & $2,42 \mathrm{dA}$ \\
\hline Isaria javanica URM4993 & $92,48 \mathrm{aA}$ & $97,60 \mathrm{aA}$ & $1,98 \mathrm{fB}$ & $2,72 \mathrm{de} A$ & $3,60 \mathrm{bB}$ & $5,28 \mathrm{cA}$ \\
\hline Isaria javanica URM4995 & $80,66 \mathrm{bcB}$ & $95,84 \mathrm{aA}$ & $1,98 \mathrm{fB}$ & $2,82 \mathrm{dA}$ & $2,04 \mathrm{bcA}$ & $2,80 \mathrm{dA}$ \\
\hline Isaria farinosa ESALQ1205 & $65,16 \mathrm{deB}$ & $88,80 \mathrm{aA}$ & $3,65 \mathrm{aB}$ & $4,16 \mathrm{bA}$ & $3,60 \mathrm{bB}$ & $5,84 \mathrm{cA}$ \\
\hline Isaria farinosa ESALQ1355 & $79,36 \mathrm{bcB}$ & $91,36 \mathrm{aA}$ & $2,76 \mathrm{cB}$ & 2,64 efA & $9,92 \mathrm{aB}$ & $13,92 \mathrm{aA}$ \\
\hline Isaria farinosa URM5060 & $60,80 \mathrm{eB}$ & $75,20 \mathrm{bA}$ & $3,26 \mathrm{bB}$ & $4,52 \mathrm{aA}$ & $1,72 \mathrm{bcA}$ & $2,72 \mathrm{dA}$ \\
\hline Isaria farinosa URM5016 & $72,64 \mathrm{cdB}$ & $92,32 \mathrm{aA}$ & $3,43 \mathrm{aB}$ & $3,67 \mathrm{cA}$ & $9,46 \mathrm{aB}$ & $11,44 \mathrm{bA}$ \\
\hline
\end{tabular}

Médias seguidas de mesma letra, minúscula na linha e maiúscula na coluna não diferem estatisticamente entre si, pelo teste de Turkey $(\mathrm{P}=0,05)$.

${ }^{1}$ Linhagem-padrão; ${ }^{2}$ Reisolado.

Já I. fumosorosea ESALQ1297 apresentou colônia de aspecto flocoso, de cor branca e reverso amarelo $(\gamma$ 19-9 $)$ (Figura 2. p, q). Essas características são semelhantes às descritas por Samson (1974), o qual constatou que I. fumosorosea forma colônia de aspecto flocoso ou pulverulento, de cor branca a coloração rósea e de reverso hialino ou amarelo creme.

A variável produção de conídios das linhagens reisoladas diferiu estatisticamente das linhagens-padrão, exceto para I. farinosa ESALQ1355, apesar que o reisolado desta linhagem produziu uma maior quantidade de conídios. Esses dados confirmam o revigoramento das linhagens após a passagem pelos insetos, cuja média de esporulação variou entre 2,00 a 13,92x 107 conídios/mL (Tabela 1). Resultados semelhantes foram obtidos por Lopes et al. (2011) quando analisaram a produção de conídos de I. javanica, 12 dias após a infecção de C. gestroi, sendo que a linhagem reisolada apresentou maior conidiogênese $\left(21,64 \times 10^{7}\right.$ conídios $\left./ \mathrm{mL}\right)$. Adicionalmente, Parker et al. (2003) avaliaram a produção de conídios de I. farinosa in vitro, isolado de Eurygaster integriceps Puton, sobre diferentes temperaturas, e constataram que as médias de esporulação variaram entre $11,7 \times 10^{7}$ e $51,5 \times 10^{7}$ conídios $/ \mathrm{cm}^{2}$ quando incubados a $25^{\circ} \mathrm{C}$. De acordo com Almeida et al. (2005), a produção de conídios viáveis em meio de cultivo e sobre cadáver de insetos é uma importante característica para análise do potencial do patógeno, e auxilia na seleção de linhagens mais virulentas a serem usadas em formulações para programas de controle de insetos-praga.

\section{Conclusão}

As linhagens de I. farinosa, I. fumosorosea e I. javanica não apresentaram alterações morfológicas após a passagem por S. zeamais, mas suas estruturas vegetativas e reprodutivas foram produzidas em maior quantidade, indicando o revigoramento dessas espécies. As linhagens apresentaram-se viáveis e revigoradas após o reisolamento a partir do gorgulho do milho, com ótimas médias de germinação de conídios, crescimento micelial e esporulação, podendo ser usadas nos bioensaios de controle biológico de $S$. zeamais.

\section{Referências}

ALMEIDA, J. C. et al. Viabilidade de Beauveria bassiana (Bals.) Vuill. reisolado de ovos, larvas e adultos de Anthonomus grandis (Boheman) (Coleoptera: Curculionidae) artificialmente infectado. Arquivos do Instituto Biológico, v. 72, n. 4, p. 473-480, 2005.

ALVES, S. B. et al. Técnicas Laboratoriais. In: ALVES, S. B. et al. Controle Microbiano de Insetos. Piracicaba: FEALQ, 1998, p. 637-710.

ALVES, S. B. Fungos entomopatogênicos. In: ALVES, S. B. et al. Controle microbiano de insetos. Piracicaba: FEALQ, 1998, p. 289-370.

ALVES, S. B.; MORAIS, S. A. Quantificação de inóculo de patógenos de insetos. In: ALVES, S. B.; MORAIS, S. A. Controle microbiano de insetos. Piracicaba: FEALQ, 1998, p. 765-777.

ALVES, S. B.; PEREIRA, R. M. Produção de fungos entomopatogênicos. In: ALVES, S. B.; PEREIRA, R. M. Controle microbiano de insetos. Piracicaba: FEALQ, 1998. p. 845-867.

BARSON, G. et al. Laboratory evaluation of six species of entomopathogenic fungi for the control of the house fly (Musca domestica L.), a pest of intensive animal units. Journal of Invertebrate Pathology, v. 64, n. 2, p. 107-113, 1994. http://dx.doi.org/10.1006/jipa.1994.1078.

DEMIRCI, F. et al. Laboratory evaluation of the effectiveness of the entomopathogen; Isaria farinosa, on citrus mealybug, Planococcus citri. Journal of Pest Science, v. 84, n. 3, p. 337-342, 2011. http:// dx.doi.org/10.1007/s10340-011-0350-9.

DOMSCH, K. H. et al. Compendium of soil fungi. San Francisco: Editora IHW-Verlag, 2007. 672 p.

FANG, W. et al. Expressing a fusion protein with protease and chitinase activities increases the virulence of the insect pathogen Beauveria bassiana. Journal of Invertebrate Pathology, v. 102, n. 2, p. 155-159, 2009.

GALLO, D. et al. Entomologia agrícola. Piracicaba: FEALQ, 2002. $920 \mathrm{p}$.

GRÄFF, C. A. et al. Patogenicidade de Isaria fumosorosea sobre o ácaro vermelho europeu em laboratório. Biotemas, v. 30, n. 1, p. 73-78, 2017. http://dx.doi.org/10.5007/2175-7925.2017v30n1p73.

HASAN, W. A.; ASSAF, L. H.; ABDULLAH, S. K. Occurrence of entomopathogenic and other opportunistic fungi in soil collected from insect hibernation sites and evaluation of their entomopathogenic 
potential. Bulletin of the Iraq Natural History Museum, v. 12, n. 1, p. 19-27, 2012.

LOPES, R. S. et al. Aspectos morfológicos de Paecilomyces farinosus (Holmex s. f. Gray) Brown \& Smith sobre infecção em Coptotermes gestroi (Wasmann) (Isoptera: Rhinotermitidae). O Biológico, v. 70, n. 1, p. 29-33, 2008.

LOPES, R. S. et al. Virulência e aspectos biológicos de Isaria javanica (Frieder\& Bally) Samson \& Hywell-Jones sobre Coptotermes gestroi (Wasmann) (Isoptera: Rhinotermitidae). Arquivos do Instituto Biologico, v. 78, n. 4, p. 565-572, 2011.

MEYLING, N. V.; SCHMIDT, N. M.; EILENBERG, J. Occurrence and diversity of fungal entomopathogens in soils of low and high Arctic Greenland. Polar Biology, v. 35, n. 9, p. 1439-1445, 2012. http://dx.doi.org/10.1007/s00300-012-1183-6.

NGAMO, T. L. S. et al. Chronic toxicity of essential oils of 3 local aromatic plants towards Sitophilus zeamais Motsch. (Coleoptera: Curculionidae). African Journal of Agricultural Research, v. 2, n. 4, p. 164-167, 2007.

PARKER, B. L. et al. Entomopathogenic fungi of Eurygaster integriceps Puton (Hemiptera: Scutelleridae): collection and characterization for development. Biological Control, v. 27, n. 3, p. 260-272, 2003. http://dx.doi.org/10.1016/S1049-9644(03)00017-3.

PASSOS, E. M. et al. Efeitos de isolados do fungo Isaria (Persoon) sobre o cupim subterrâneo Coptotermes gestroi (Wasmann) (Isoptera: Rhinotermitidae). Arquivos Instituto Biológico, v. 81, n. 3, p. 232-237, 2014. http://dx.doi.org/10.1590/1808-1657000642012.

POTRICH, M. et al. Avaliação de Beauveria bassiana (Bals.) vuill. e Metarhizium anisopliae (Metsch.) Sorok para controle de Sitophilus zeamais (Coleoptera: Curculionidae). Bioassay, v. 1, n. 12, p. 1-9, 2006. http://dx.doi.org/10.14295/BA.v1.0.34.

POTRICH, M. et al. Seleção e associação de cultivares de milho com Beauveria bassiana para o controle de Sitophilus zeamais (Coleoptera: Curculionidae). Semina: Ciências Agrárias, v. 31, n. 1, p. 5-18, 2010. http://dx.doi.org/10.5433/1679-0359.2010v31n1p5.

RONDELLI, V. M. et al. Selection of Beauveria bassiana (Bals.) Vuill. isolates for controlling Sitophilus zeamais (Mots.) (Coleoptera:
Curculionidae). Idesia, v. 30, n. 3, p. 97-102, 2012. http://dx.doi org/10.4067/S0718-34292012000300013.

SAMSON, R. A. Paecilomyces and some allied Hyphomycetes. Studies in Mycology, v. 6, n. 6, p. 1-119, 1974.

SCORSETTI, A. C. et al. New records of entomopathogenic fung infecting Bemisia tabaci and Trialeurodes vaporariorum pests of horticultural crops in Argentina. BioControl, v. 53, n. 5, p. 787-796, 2008. http://dx.doi.org/10.1007/s10526-007-9118-9.

SPECHT, A. et al. Ocorrência do fungo entomopatogênico Isaria javanica (Frieder\& Bally) Samson \& Hywell-Jones (Fungi, Sordariomycetes) em lagartas de Lonomia obliqua Walker (Lepidoptera, Saturniidae, Hemileucinae). Revista Brasileira de Entomologia, v. 53, n. 3 , p. 493-494, 2009.

SZENTIVÁNYI, O. et al. Paecilonyces farinosus destroys powdery mildew colonies in detached leaf cultures but not on whole plants. European Journal of Plant Pathology, v. 11, n. 3, p. 351-356, 2006. http://dx.doi.org/10.1007/s10658-006-9011-x.

VILLALOBOS-DOMINGUEZ, C.; VILLALOBOS, J. Atlas de los Colores. Buenos Aires: El Ateneo, 1947. 76 p.

WRIGHT, S. M.; LAX, R. A. Combined effect of microbial and chemical control agents on subterranean termites. Journal of Microbiology, v. 51, n. 5, p. 578-583, 2013. http://dx.doi.org/10.1007/ s12275-013-2628-5.

XU, D. et al. Insecticidal activity influence of 20-Hydroxyecdysone on the pathogenicity of Isaria fumosorosea against Plutella xylostella. Biological Control, v. 56, n. 3, p. 239-244, 2011. http://dx.doi. org/10.1016/j.biocontrol.2010.11.011.

YANG, S. et al. Insecticidal efficacy of Isaria farinosa in different life stages of Pissodes puctatus (Coleoptera: curculionidae). Journal of Pest Science, v. 83, n. 4, p. 321-325, 2009. http://dx.doi.org/10.1007/ s10340-009-0256-y. 